\title{
The Intelligent use of RFID and BIM in Prefabricated, Prefinished, Volumetric Construction Work Flow
}

\author{
Ernest L S A bbott ${ }^{1 *}$, and David $K H_{\text {Chua }}{ }^{1}$ \\ ${ }^{1}$ Department. of Civil \& Environmental Engineering. National U niversity of Singapore, Singapore
}

\begin{abstract}
RFID is used in many areas of commerce, and in some areas of the construction industry. Prefabricated, prefinished volumetric construction (PPVC) is one area of the construction industry that can benefit from the use of RFID. The full benefits cannot be realised by the use of RFID alone. RFID needs to be coupled with Building Information Modelling (BIM ). This paper outlines a framework of marrying the two technologies in constructing PPV C from the drawing stage to the delivery on site and then to the final installation of the unit. The benefits of this union are in material stock control, part location tracking, production scheduling and re-scheduling, among other things.
\end{abstract}

Keywords: BIM, RFID, volumetric construction, intelligent logistics, PPVC.

\section{Introduction}

RFID's origins can be traced to the work on RADAR during the second world war [1, 2]. In 1948 Harry Stockman seminal paper, "Communications by means of reflective power" [3], suggested what is today RFID, although he fully recognized the technical problems involved, as it was not until the 1970s that Stockman's ideas started to come to fruition [4].

Since the 1970s, RFID usage has grown to fill almost every corner and aspect of life, including agriculture and livestock, defence and security, healthcare and welfare, transportation and identification system [4]. It was as long ago as 1995 that Jaselskis et al. [5] discussed the use of RFID tags in the construction industry. Since then the technology of not only the tags but also the RFID readers have seen dramatic improvements, not just in size and ability but also in a reduction in cost. The various suggestions of Jaselskis et al. were clearly limited by the then cost of using RFID. Their proposal of tagging large objects, such as gas cylinders and Concrete Trucks for tracking truck movements on and off-site illustrates this.

RFID tags have a clear advantage over other identification systems such as Bar Codes or QR codes, as they rely upon electromagnetic fields and not a line of sight. RFID tags may be

*Coresponding author: ceeaels@ nus.edu.sg 
active, semi-active, passive or semi-passive. Each tag type operates at a different frequency. Active RFID tags have a battery as a power source. Passive tags do not have a power source. For ease of understanding, semi-active tags can be considered as active tags without a battery, and semi-passive tags as passive tags with a battery [6]. This is summarised in Table 1 .

The passive RFID is the most common tag. The cost, depending on purchase volume, is between US\$0.07 and US\$0.15 $5^{\dagger}$. The passive RFID is the one used in the foregoing discussion.

Building Information Modelling or BIM has been defined in several ways. John Eynon defines BIM as "Building Information Modelling is the digital representation of physical and functional characteristics of a facility creating a shared knowledge resource for information about it and forming a reliable basis for decisions during its life cycle, from earliest conception to demolition" [7]. This is the working definition used in this paper.

Several AEC software packages support BIM. Revit, Tekla, Bentley and Archicad are just four examples of widely used packages. Tekla Structures is the AEC software package used in this paper for the design of prefabricated, prefinished, volumetric construction (PPVC).

PPVC is usually used for multilevel constructions such as medium to high-rise residential buildings. The modules are cast and assembled at a production location. All finishes, such as plumbing, sanitary ware, electrical and HAVC, are installed prior to the units being delivered and installed at a construction site. The benefits are really at the construction site level where there is a reduction in manpower compared with in-situ construction and environmentally, there is a reduction in construction noise and dust.

Błąd! Nie można odnaleźć źródla odwołania. illustrates a floor slab and three walls each cast separately. Fig. 1 illustrates the assembly of a module comprising of a floor slab and three walls. Following the necessary fitting out, the completed module is transported to site where it is installed at its predefined location.

BIM models are data-rich. RFID is used to identify each component of a module. This paper sets out a framework for marrying RFID and BIM, giving a synergy that greatly benefits its users.

Table 1. Summary of RFID Tag Types

\begin{tabular}{ccc}
\cline { 2 - 3 } Emitted Energy & $\begin{array}{c}\text { Semi-A ctive. Tags become } \\
\text { temporally active when they receive } \\
\text { "power" from an RFID reader. }\end{array}$ & $\begin{array}{c}\text { A ctive. Tags transmit a signal to be } \\
\text { read by an RFID reader. The tag data } \\
\text { can be read at distances of } 30 \text { meters } \\
\text { or greater. }\end{array}$ \\
\hline Reflective Energy & $\begin{array}{c}\text { Passive. Tags receive "power" from } \\
\text { an RFID reader. The data is } \\
\text { transmitted by reflecting this power } \\
\text { from the reader. (this is known as } \\
\text { backscatter modulation.) Data can be } \\
\text { read up to about 6 meters. }\end{array}$ & $\begin{array}{c}\text { Semi-Passive. This is al so known as } \\
\text { battery-assisted passive (BAP). The } \\
\text { data is read from the tag in the same } \\
\text { way as the passive tag. The battery is } \\
\text { used for its operating pow er. Data } \\
\text { can be read at distances of more than } \\
\text { 30 meters. }\end{array}$ \\
\hline
\end{tabular}

\section{The Framework}

The marrying of RFID technology with BIM in the area of PPVC allows a systematic approach to monitoring, managing and optimizing all aspects of the factory environment, delivery to site and installation of modules. 
Fig. 2 shows an outline of the proposed framework. The Tekla BIM model, with details of PPVC units, is imported to a central database. The importation of the site installation schedule and the PPVC unit data are used to generate an optimised factory production schedule in order to effect a JIT delivery at the construction site. All material quantities, from the BIM data, allows for the minimization of stock holding costs through prudent stock control. Drawing changes, leading to part modification or scrapping, are readily tracked using the parts RFID.

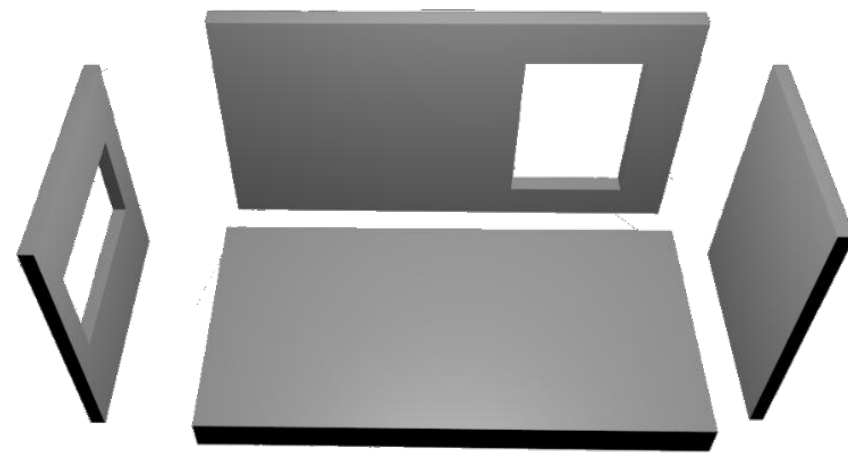

Fig. 1. PPVC M odule before A ssembly

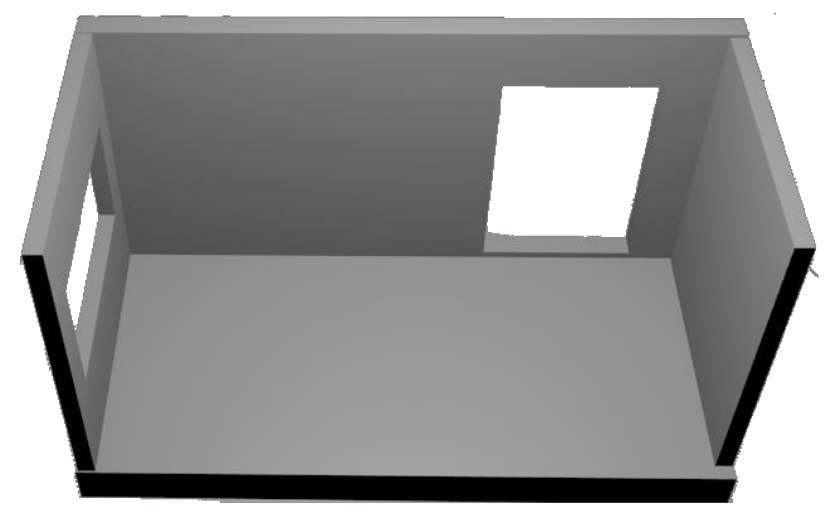

Fig. 1. PPVC M odule after A ssembly 


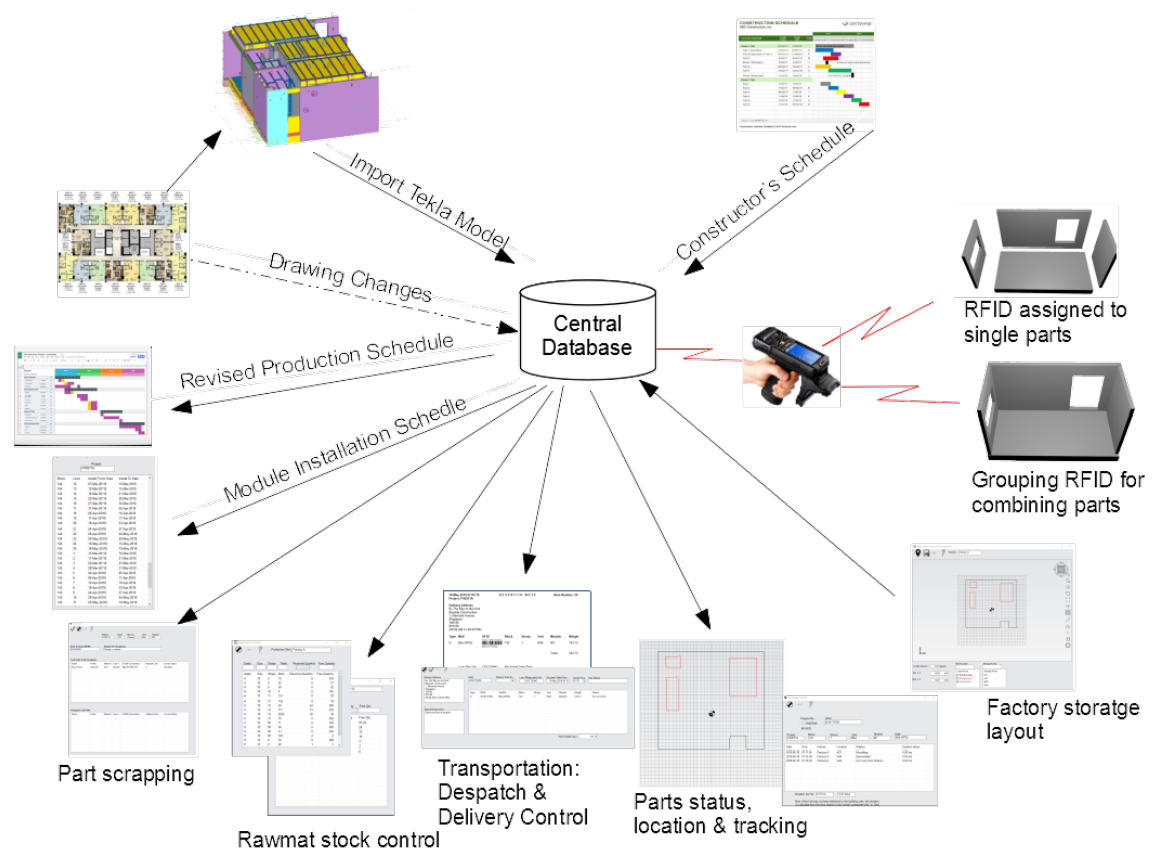

Fig. 2. Outline of Proposed Framework

\section{Deriving the PPVC Module Production Schedule}

The PPVC module production schedule is calculated from the broad installation schedule, which indicates an installation period for the block. The storey installation cycle is calculated as in equation (1)

$$
\text { Storey Installation Cycle }=\frac{\text { Number of Working Days in Installation Period }}{\text { Number of Storeys in Block }}
$$

The PPVC factory needs to supply the building site with modules, at the required intervals to meet the storey installation cycle.

From BIM, the number of components, walls, slabs, etc, are extracted, and a production schedule is generated. For an optimal production schedule to be generated, additional information on the factory layout pertaining to the area available for casting moulds, storing moulds, for assembling PPVC components into modules is required. Space is one metric, the other is time, i.e. the time for the various operations, e.g. fitting out the mould, pouring concrete, time to demoulding, time for curing, time for assembling into modules, time to fit out the modules ready for final installation and transportation time. Any subcontractor's information will also need to be included if one is used.

\section{Extracting BIM Data}

The digital model created by the designer, using propriety software, is not in a suitable format for some subsequent process. Although the model contains ample information, propriety software is not designed as a general database. To overcome this, relevant model data is extracted from the BIM and stored in a suitable form on a central database. 
This paper is concerned with residential properties. The extracted database identifies modules, storey location of the module, the residential block identity, and the propriety software's unique identity of the part.

\section{Module Production and RFID Tracking}

Fig. 3 illustrates the schematic for RFID allocation and tracking at all stages of the production of a PPVC module. The process begins by applying an RFID tag at the point the part is moulded. (The tag is readable, provided it is more than $3 \mathrm{~mm}$ from rebar, or any other metallic object. Any metallic object too near an RFID tag will interfere with the tag's operation.)
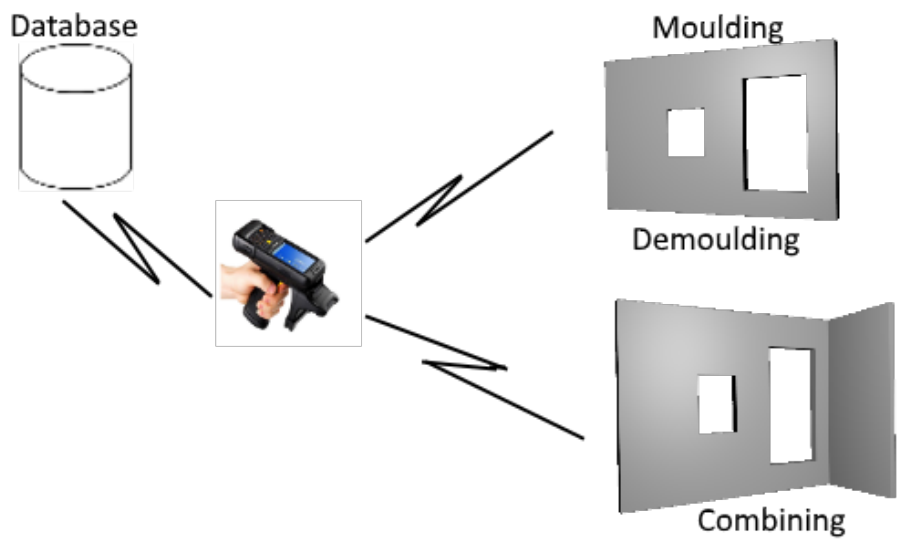

Fig. 3. RFID Tracking at A II Stages of Production

Once an RFID tag is added to a part, and the computer system is notified, the part becomes trackable. The RFID reader used to read the tags, is connected, either directly or wirelessly, to a computer system, which maintains pertinent information on the status of module parts.

RFID tags are registered, in the computer system, to a specific location. This is important, particularly when more than one PPVC production site is used.

The registration of the tag is prior to using the tag on a module part. When the RFID tag is attached to a part, the RFID reader reads the tag, which links the part on the computer system to the RFID tag as well as its BIM identity. Following any change in the status of a part, the part's RFID is scanned and the status, eg moulding, demoulding, location in the factory, destination when being transported, is updated.

PPVC modules, or combined parts, but not whole modules, can be transported for a number of reasons. For example, the parts were produced at different production sites. The fitting out of the assembled module is done at a different location to the production location.

Each component part of a PPVC module has its own unique RFID tag. Parts are not necessarily assembled into a final module in one operation. Walls may be joined together before being joined to a floor slab, for example. When parts are joined, their association is recorded in the computer system. RFIDs are linked in the computer system in such a way that identifying just a single part, identifies all linked associated parts. In this way, only one part needs to be scanned for every module or group of parts to enable status updating or location identification for example.

The RFID tag is automatically linked to the BIM component. When assembling parts to compose a module, an authentication check is performed, ensuring the correct matching of mould parts to a module 


\section{Delivery and Site Installation}

Completed and fitted out PPVC modules are transported to the construction site. This is a status change in the module and all parts that comprise the module. Using the RFID of the module (i.e. any part on the module), a despatch manifest is computer generated. Upon arrival at the delivery point, the module's RFID is read and they verified against the original delivery information.

Completed PPVC modules are delivered to the construction site. At the construction site, any part's RFID is read to identify the module and its intended installation location in the development. The installation location is obtained from the BIM model data of the development.

\section{Material Stock Control}

The BIM model of a residential development holds the materials used in the various parts, such as the rebar sizes and lengths and the type of concrete used. The physical measurements of panels, length, width, height and volume are also found in the BIM model. Once the BIM model has been completed, the total quantities of material required for the construction can be calculated. This value can be used as a guide to the cost of production, for example. This information combined with the PPVC production schedule gives a guide as to the periodic stock requirement.

Each PPVC production location holds stock of some material, such as sand, cement, agate and fly ash. Rebars cages and steel frames are often delivered to order. As module parts are moulded, the RFID is the key to identifying the point of moulding, the stock required to construct the prefabricated part can be depleted from the total stock held. The RFID links to a given part, whose construction quantities are calculated from the BIM data.

There are several methods of stock control. One method is using the free stock approach. This, coupled with delivery lead times of stock and minimum order quantities, facilitates a more systematic method of stock control, based on what is built. It also enables the factory to minimize their stock holding cost.

\section{Scheduling and Rescheduling}

Schedule disruption has many causes. Changes in design being one of them. If there is a change in a module design after the production of the module has started, this has an impact on the overall production schedule. The extent of which depends on the extent of the design change. Using the BIM model, the design change can be identified, by means of versioning. All parts that have been moulded, and their current status, are identifiable via their RFID. The impact of changes on the schedule depends on whether the module part can be modified or has to be scrapped. Modifying already moulded parts will often have a minor impact on the schedule and stock. The scrapping of whole modules can cause delays in the schedule as well as having an impact on the raw material stock.

The cost of scrapping is the material cost of the components plus the labour cost. The raw material cost is the product of the raw material content, which is from BIM, and the unit cost of the raw material, which is held on a database. The labour cost calculation depends on the method adopted by the company. 


\section{Case Study}

The case study will not cover all the framework. It will cover the core of the framework; the extraction of BIM model data, the assignment of RFID to parts, stock control, despatch and delivery of parts/modules.

\subsection{Extracting the BIM Model}

Fig. 4 shows a residential unit modelled in Tekla. The residential unit consists of three modules. The modules comprise of concrete walls, reinforcement bars, pipes, steel frames and other smaller parts. Fig. 5 views the same residential unit after it has been imported into the computer system.

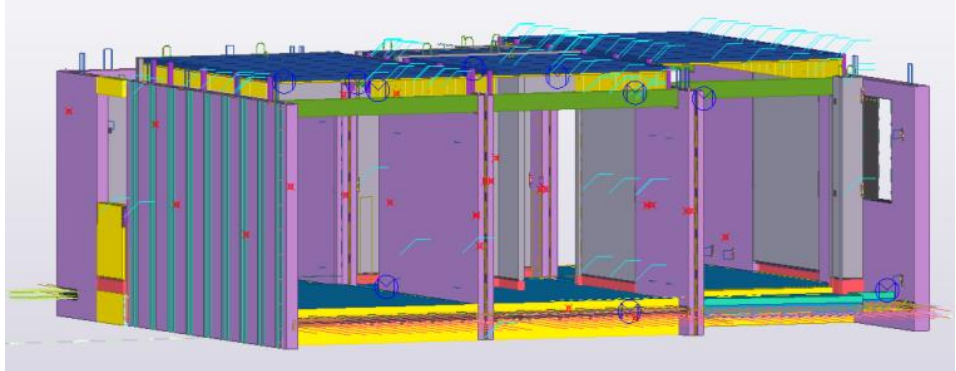

Fig. 4. Unit of Three M odules Viewed in Tekla

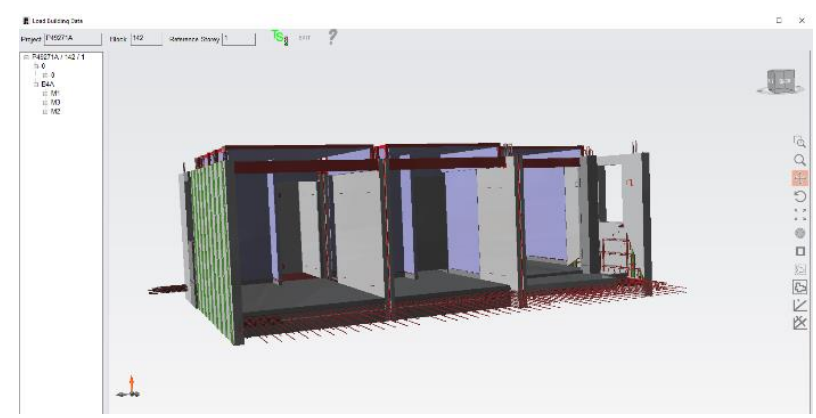

Fig. 5. U nit as Imported to Computer System

\subsection{Registering RFID Tags}

The registering of the RFID tags is at any point prior to their use. Fig. 6 illustrates 10 RFID tags registered to production site A. These tags will have their first use at production site A. The location of the tag changes when the part the tag is assigned to changes its location. 


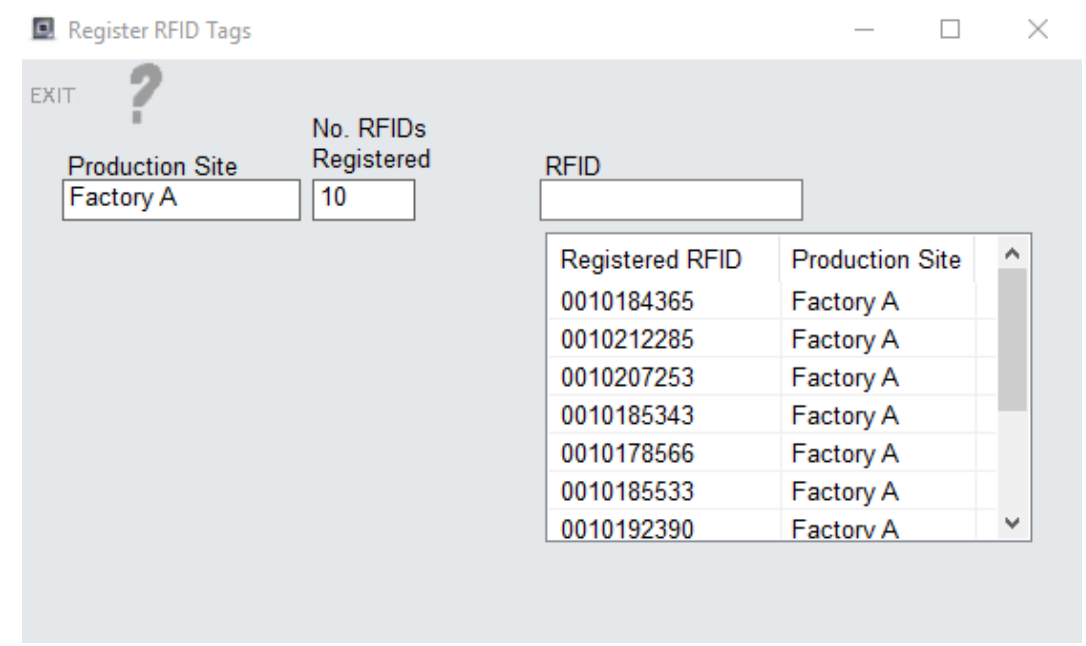

Fig. 6. RFID Tags Registered to a Production Site

\subsection{Assigning RFID Tags to Parts}

At part moulding time, an RFID tag is attached or embedded in the concrete. The tag is scanned. Fig. 7 shows the assignment of an RFID tag to a component wall. The cast wall's constituent parts are also shown.

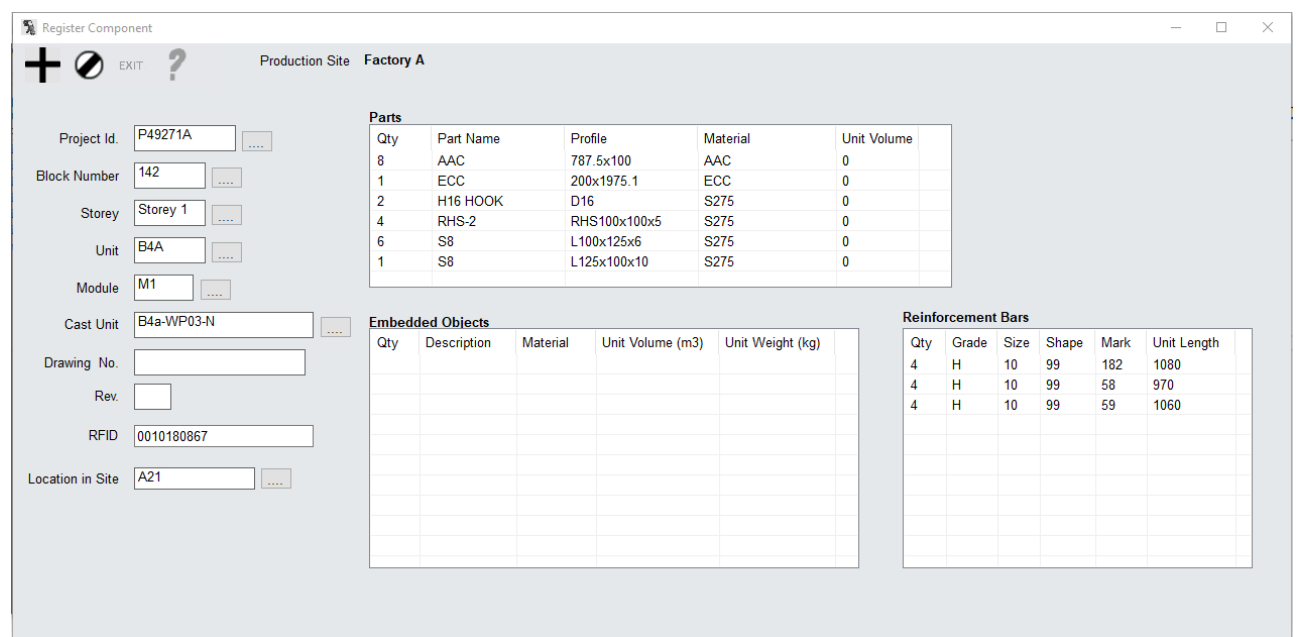

Fig. 7. RFID Assigned to a Part

\subsection{Part Status}

The RFID tag is assigned at moulding time. At demoulding time, the RFID tag is read and the status is changed to demoulded. The part location is also updated. Fig. 8 is the general part status change, which is used anytime there is a change in a part status. The RFID tag is scanned and the current status is displayed

When an RFID tag is assigned to a moulded part, the raw materials used in the part are automatically adjusted. Fig. 9 illustrates the current rebar stock and Fig. 10 illustrates the 
current raw material stock. The composition of the concrete is stored on a database. This is used, with BIM data, to calculate the quantities by which to deplete the stock.

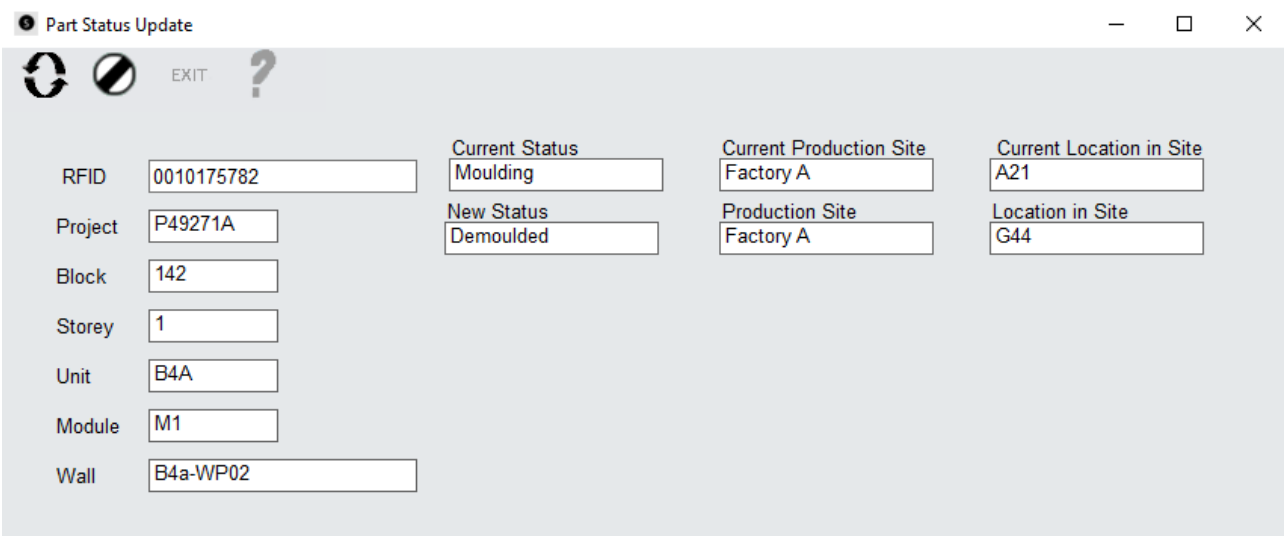

Fig. 8. Part Status Change

\section{Stock Enquires}

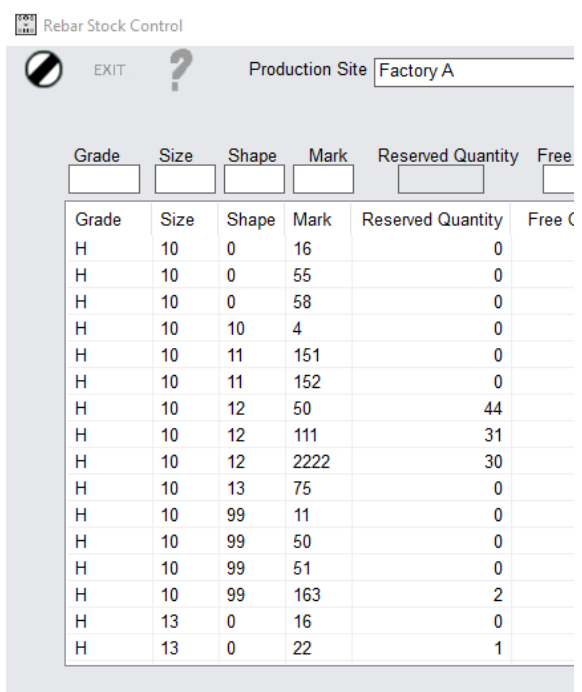

Fig. 9. Rebar Stock Status Enquiry

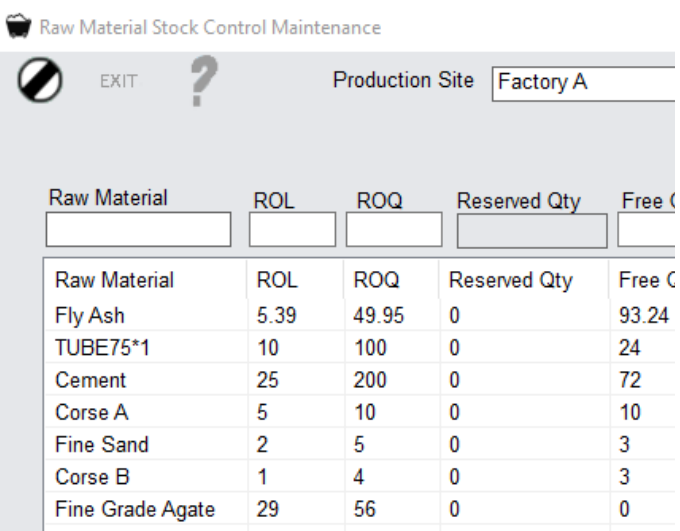

Fig. 10. Raw M aterial Stock Status Enquiry

\subsection{Parts Transportation}

RFID is used to identify the parts loaded onto a lorry for transportation from one location to another. The lorry loading details are quickly produced directly from scanning the part or parts. For module parts that are joined to other module parts, the scanning of just a single RFID is sufficient to identify all joined parts. Fig. 11 illustrates the identification of parts to compose a lorry load. Once the despatch information is printed, as illustrated in Fig. 12, the status of the parts is automatically updated to show the part is on a particular lorry. Figure 13 
illustrates the arrival of a lorry load at a site. The parts' RFID is read directly, or the bar code on the despatch note is read. The part status is updated.

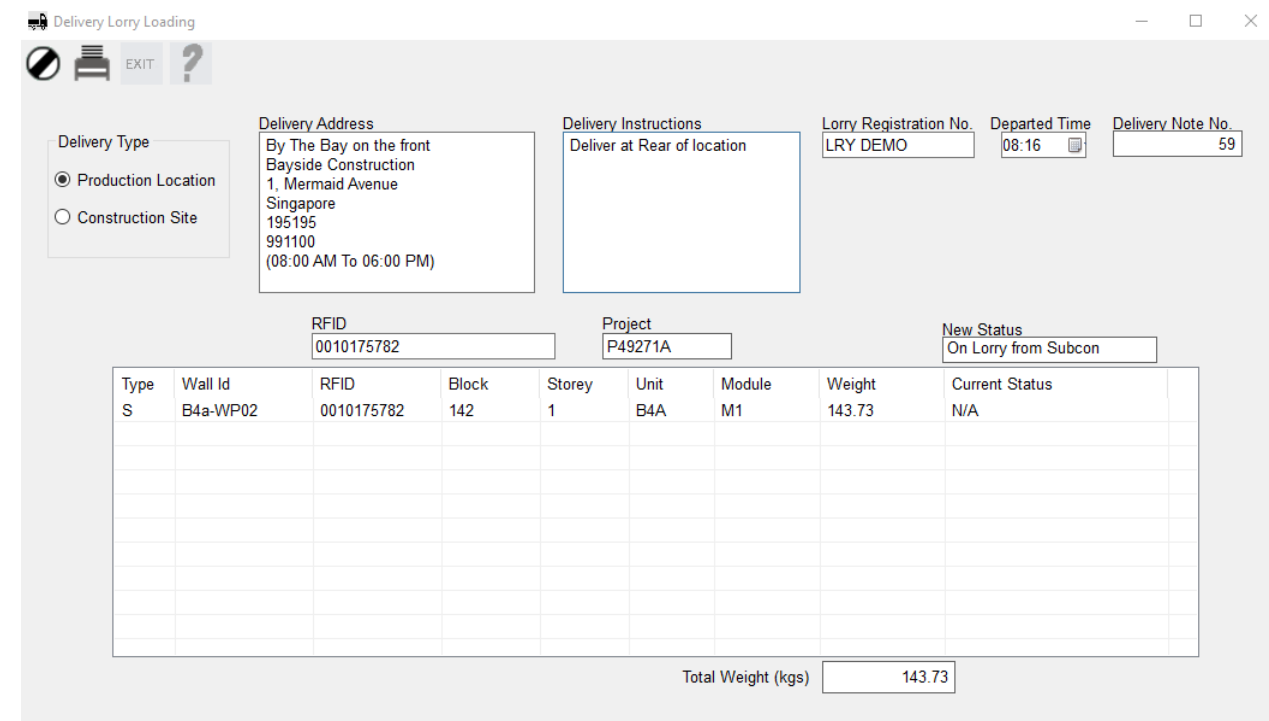

Fig. 11. Lorry Loading for Part Transportation

\begin{tabular}{|c|c|c|c|c|c|c|c|}
\hline \multicolumn{2}{|c|}{$\begin{array}{l}\text { 18-May-2018 07:05:19 } \\
\text { Project: P49271A }\end{array}$} & \multicolumn{4}{|c|}{ DESPATCH NOTE } & \multicolumn{2}{|c|}{ Note Number: 59} \\
\hline \multicolumn{8}{|c|}{$\begin{array}{l}\text { Delivery Address } \\
\text { By The Bay on the front } \\
\text { Bayside Construction } \\
\text { 1, Mermaid Avenue } \\
\text { Singapore } \\
195195 \\
991100 \\
\text { (08:00 AM To 06:00 PM) }\end{array}$} \\
\hline Type & Wall & RFID & Block & Storey & Unit & Module & Weight \\
\hline \multirow[t]{3}{*}{$S$} & B4a-WP02 & $\underset{0010175782}{\||\||||||||||||||||||||}$ & 142 & 1 & B4A & M1 & 143.73 \\
\hline & & & & & & Total: & 143.73 \\
\hline & Lorry Reg. No.: & LRY DEMO & \multicolumn{2}{|c|}{ Received Date/Time } & & & \\
\hline \multicolumn{3}{|c|}{ Deliver at Rear of location } & Co. Chop. & & & & \\
\hline
\end{tabular}

Fig. 12. Sample Despatch Note 


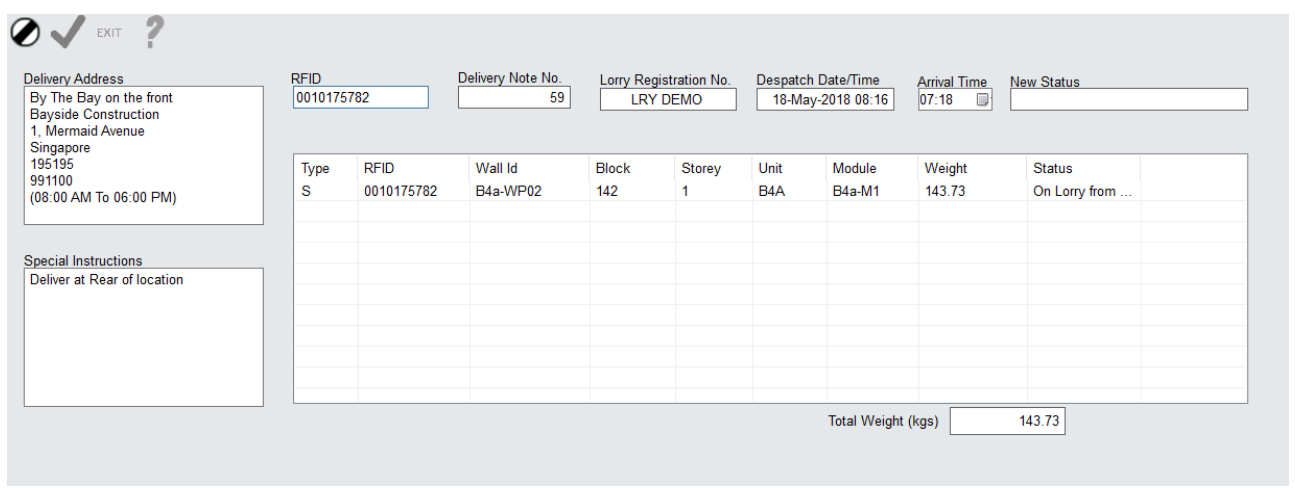

Figure 13. Delivery to Site

\section{Conclusion \& Future Work}

The framework outlined in this paper has shown the positive benefits of marrying together two technologies, RFID and BIM, which gives a firm foundation for the optimization of all aspect of the construction, delivery and installation of PPVC units as well as ensuring the correct part is assembled with its intended module. With component identification, at the point of production, leading to full tracking of all processes and statuses of the component, analysis of the efficiency of the production process can be readily analysed with remedial steps taken to improve workflow efficiency.

The framework outlined here has not covered all areas, due to space and time constraint. The areas omitted are the algorithms for the efficient production of the PPVC modules. There are several scenarios to consider in this respect; (i) sufficient factory capacity for continuous production by building storey, (ii) sufficient factory capacity but insufficient manpower/time for continuous production, (iii) insufficient factory space for continuous production by building storey, (iv) optimization of moulds, rather than using mould sets, i.e. all moulds for a module.

\section{References}

1. M. R oberti, The History of RFID Technology The History of RFID Technology, Energy, 1-3 (2005), http://www .rfidjournal.com/article/view/1338/1

2. J. Landt, The History of RFID, IEEE Potentials 24(4):8-11 (2005)

3. H. Stockman, Communication by M eans of R eflected Power, In Proceedings of the IRE 36(10):1196-1204 (1948), doi:10.1109/J RPR OC.1948.226245.

4. K. Jung, S. Lee, A Systematic Review of RFID Applications and Diffusion: K ey A reas and Public Policy Issues, Journal of Open Innovation: Technology, Market, and Complexity 1(1):9 (2015)

5. E. Jaselskis, M.R. A nderson, C.T. Jahren, Y. Rodriguez, S. Njos, Radio- Frequency Identification Applications in Construction Industry, Journal of Construction Engineering and Management 121(2):189- 196 (1995)

6. R. Bridelall, A. Hande, Performance M etrics and Operational Parameters of RFID Systems Itle, In RFID Systems: Research Trends and Challenges, edited by Miodrag B olic, David Simplot-Ryl, and Ivan Stojmenovic, 23-56, John Wiley \& Sons L td (2010)

7. J. Eynon, Construction Manager's BIM Handbook, John Wiley \& Sons L td (2016) 


\section{Acknowledgements}

The authors acknowledge the financial support by the National Research Foundation (NRF) and SembC orp-NUS Corp L ab under project grant R-261-513-009-281. 